\title{
Morphological, Rheological, and Mechanical Properties of Polyamide 6/Styrene-Acrylic Acid Copolymer Blends
}

\author{
Won Ho Jo, Hong Gyun KIM, and Suk Hoon CHAE \\ Department of Fiber and Polymer Science, Seoul National University, \\ Seoul 151-742, Korea
}

(Received January 18, 1993)

\begin{abstract}
The morphology, rheological and tensile properties of polyamide 6 (PA6)/poly(styrene-co-acrylic acid) (SAA) blends were examined as a function of the acrylic acid (AA) content in SAA. It was found that the AA unit in copolymers has a pronounced effect upon the morphology of the blends. The dispersed phase size was significantly reduced with increasing AA content in SAA. A reduction in the particle size of the dispersed phase resulted in improvement in tensile properties of the blends.
\end{abstract}

KEY WORDS Morphology / Rheological Properties / Tensile Properties /

Polyamide 6 / Poly(styrene-co-acrylic acid) / Domain Size / Chemical

Reaction / Long Branching /

Polystyrene (PS) and polyamide 6 (PA6) are two important classes of polymers. PS is widely used as an injection molding and vacuum forming material due to low cost, good moldability, low moisture absorption, good dimensional stability, good electrical insulation properties, and colorability. The principal limitations of PS, however, are its brittleness, inability to withstand the temperature of boiling water and mediocre oil resistance. PA6 is an engineering thermoplastic material. It finds many applications in eletrical, mechanical, and automotive parts due to its very high strength, wear and heat resistance, ease of fabrication, and excellent barrier properties to oils. However, it has not become a commodity plastic material because of its relatively high cost. Therefore it is desirable to compromise properties and cost by blending PS and PA6.

It is often difficult to obtain good dispersion in polymer blends whose components are essentially insoluble in each other, particularly for blends of a polar polymer such as PA6 with a nonpolar polymer such as PS. Several authors ${ }^{1-9}$ have reported that the presence of a block or graft copolymer of appropriate chemical structure provides lowering of the interfacial energy and an improvement of the interfacial adhesion between the two phases. The final morphological effect is reduction in particle size of the dispersed phase in the blend. For example, in the case of polystyrene (PS)/polyethylene (PE) blends, Heikens et al. ${ }^{7}$ observed that the dimensions of the PE domains decreased with the addition of PSco-PE graft and block coplymers. Recently attempts were made to compatibilize immiscible polymer pairs by introducing a specific interaction between constituents of individual polymer chains. It has been reported that copolymers of methyl methacrylate and 4-vinylpyridine were miscible poly(butyl acrylate-co-acrylic acid) through specific interaction. ${ }^{10}$

In this work, acrylic acid (AA) was introduced into PS to enhance the compatibility of PA6 and PS blend, and the morphology, rheological and tensile properties of PA6/SAA blends were examined as 
functions of AA content in SAA.

\section{EXPERIMENTAL}

\section{Materials}

$\operatorname{PS}\left(M_{w}=2.0 \times 10^{5} \mathrm{~g} \mathrm{~mol}^{-1}, T_{\mathrm{g}}=104^{\circ} \mathrm{C}\right)$ and PA6 $\left(M_{w}=1.8 \times 10^{4} \mathrm{~g} \mathrm{~mol}^{-1}, T_{\mathrm{g}}=42^{\circ} \mathrm{C}, T_{\mathrm{m}}=\right.$ $223^{\circ} \mathrm{C}$ ) were obtained from Aldrich Co. and Tong-Yang Nylon Co. (Korea) respectively, and used as received without further purification. SAA was synthesized in a sealed glass ampule by bulk polymerization at $60^{\circ} \mathrm{C}$ using benzoyl peroxide as an initiator. The maximum degree of conversion was controlled to $c a$. $15 \mathrm{wt} \%$. The acrylic acid content in the copolymer was determined by titration in tetrahydrofuran (THF) with a standardized methanolic $\mathrm{NaOH}$ solution using phenolphthalein indicator. SAA copolymer composition and other properties are listed in Table I.

\section{Preparation of Blends}

PA6/PS blends and PA6/SAA's blends were melt mixed in a Rheomix 600 (Haake Buchler Instrument Inc.). Approximately $60 \mathrm{cc}$ of the dried polymers were added to the preheated Rheomix mixing head at $240^{\circ} \mathrm{C}$ and allowed to flux for $10 \mathrm{~min}$ at $100 \mathrm{rpm}$.

\section{Morphological Observations}

The morphology of PA6/PS and PA6/SAA's blends was obeserved with a JEOL JSM-35 scanning electron microscope (SEM). The

Table I. Compositions, molecular weights and $T_{\mathrm{g}} \mathrm{s}$ of SAAs

\begin{tabular}{cccc}
\hline \multirow{2}{*}{$\begin{array}{c}\text { Sample } \\
\text { code }\end{array}$} & \multicolumn{2}{c}{ Comp. (AA) } & \\
\cline { 2 - 4 } & wt $\%$ & & \\
& & & \\
\hline SAA3 & 3.4 & 3.2 & 110 \\
SAA5 & 5.0 & 2.5 & 112 \\
SAA10 & 10.0 & 2.1 & 120 \\
SAA15 & 15.2 & 1.4 & 126 \\
\hline
\end{tabular}

a Compositions were determined by titration.

b The weight average molecular weight determined by GPC. samples were fractured at the liquid nitrogen temperature and the fracture surface was treated with THF or formic acid at room temperature for 30 seconds in order to remove the minor phase. The suface was coated with gold and the accelerating voltage was $25 \mathrm{kV}$.

\section{Rheological Measurements}

The melt rheological properties of the homopolymer and blends were determined at $240^{\circ} \mathrm{C}$ in a Rheometrics Dynamic Spectrometer with parallel plate mode. Parallel plate goemetry is $1.2 \mathrm{~mm}$ in gap size and $2.5 \mathrm{~cm}$ in diameter. The samples were compressionmolded into discs of $2.5 \mathrm{~cm}$ in diameter and $2 \mathrm{~mm}$ thick. Strain was maintained to $15 \%$ for all of the samples.

\section{Tensile Testing}

Tensile properties such as initial modulus, tensile strength, and elongation at break were measured on an Instron Model 4201 universal testing machine. Measurements were made at room temperature at a constant cross-head speed of $10 \mathrm{~cm} \mathrm{~min}^{-1}$ on specimens with a gauge length of $3.0 \mathrm{~cm}$. The melt-mixed blends were compression-molded into a film of $0.3 \mathrm{~mm}$ in thickness at $240^{\circ} \mathrm{C}$ and then quenched into liquid nitrogen to avoid crystallization of PA6. Specimens were cut from the film that had a width of $0.5 \mathrm{~cm}$ and length sufficient to give a gauge length when installed in the grips of the Instron. All specimens were conditioned at standard conditions before tensile testing to retain the same moisture region. The data were taken as averages of at least five tests.

\section{RESULTS AND DISCUSSION}

\section{Morphology}

The scanning electron micrographs of fractured surfaces of PA6/PS blends show the typical morphology of an incompatible blend, as shown in Figure 1. Figure $1 \mathrm{a}$ and $1 \mathrm{~b}$ show that the PS domain has a well defined spherical shape. The domain surface and surface of holes 

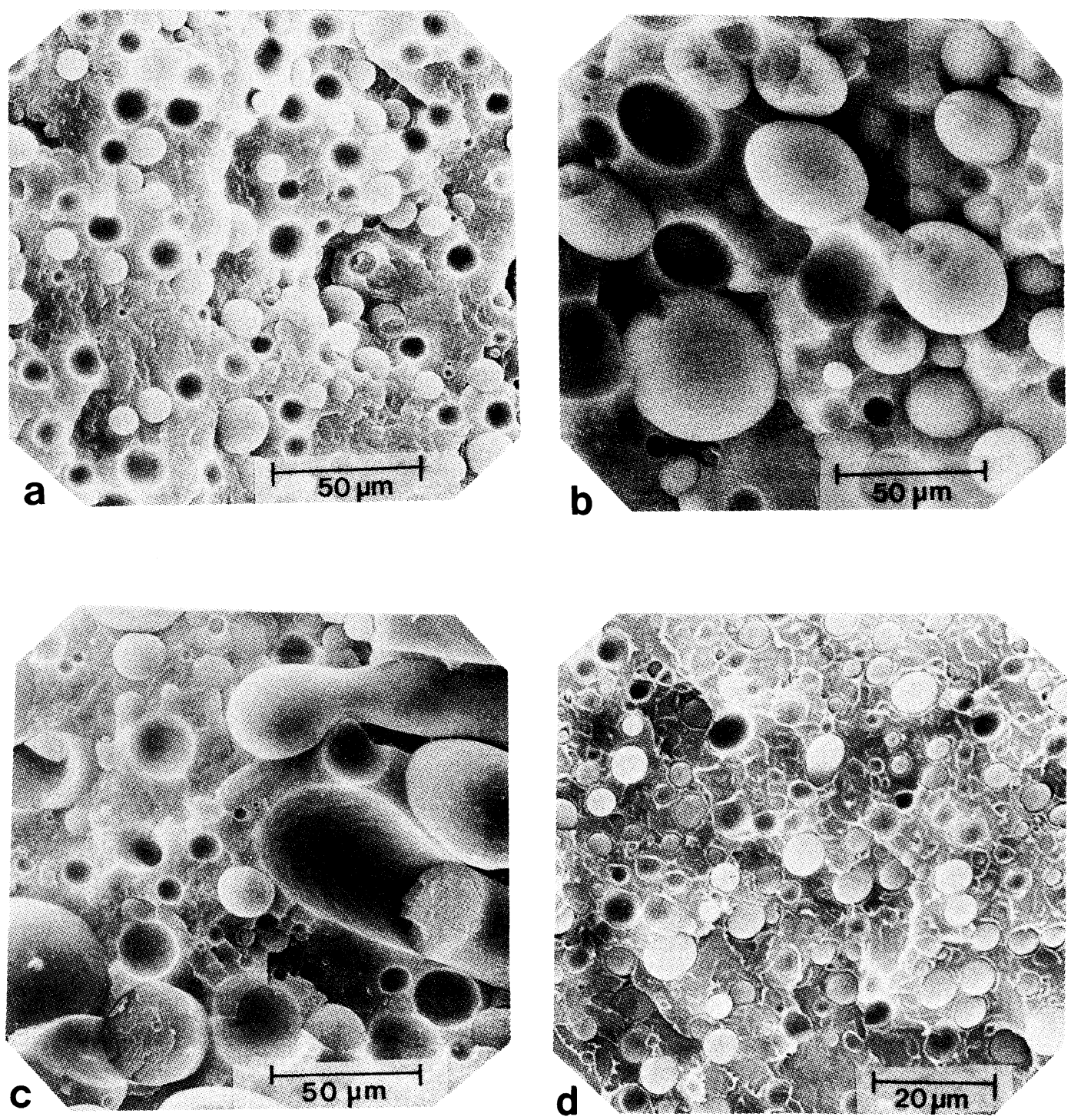

Figure 1. Scanning electron micrographs of fracture surfaces of PA6/PS blends: (a) PA6/PS (80/20), (b) PA6/PS (60/40), (c) PA6/PS (40/60), (d) PA6/PS (20/80).

left by the PS spheres appear to be very smooth. In addition, during the fracture process, a large number of domains were pulled away from their previous position. This observation suggests poor adhesion between the PS phase and PA6 matrix. The PS domains of a PA6/PS $(80 / 20)$ blend have a diameter of $5-15 \mu \mathrm{m}$ and domain size distribution is very broad. When one compares Figure 1a with Figures $1 \mathrm{~b}$ and $1 c$, it is realized that the dimensions of the PS domain not only increase but also attain a broader distribution. Figure 1d shows the morphology of a PA6/PS $(20 / 80)$ blend in which the phases of the blend were inverted.

The fracture surfaces of PA6/PS and PA6/ SAA's blends, followed by minor phases disso- 

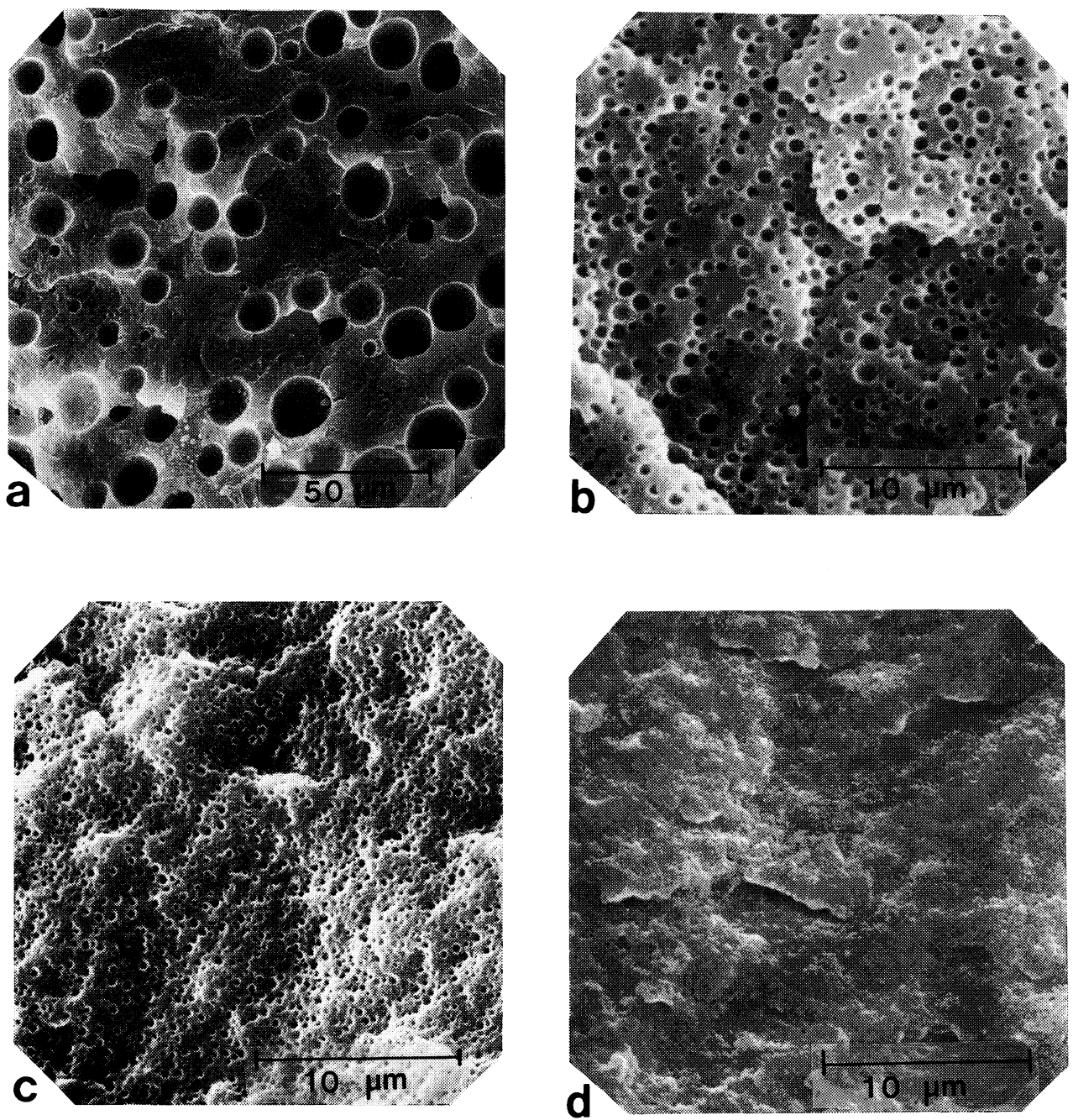

Figure 2. Scanning electron micrographs of fracture surfaces of blends, followed by minor phase dissolution: (a) PA6/PS (80/20), (b) PA6/SAA3 (80/20), (c) PA6/SAA10 (80/20), (d) PA6/SAA15 (80/20).

lution, are shown in Figure 2. When the morphology of a PA6/PS (80/20) blend (Figure $2 a)$ is compared with that of a PA6/SAA3 $(80 / 20)$ blend (Figure $2 b)$, it is observed that the average size of the dispersed phase is reduced to one-twentieth. Furthermore, the domain size of the dispersed phase decreases with increasing AA content in SAA copolymer. It is noteworthy that the fracture surface of a PA6/SAA15 (Figure 2d) blend shows no discernible domains, indicating compatibility at this scale.
The blend system of PA6 and PS appears to be similar in many respects to the system of PA6 and PE. Both consist of different phases caused by the intrinsic incompatibility of the components. PA6/PE blends are prepared in an attempt to retain the most desirable properties of both polymers, while avoiding major drawbacks. In fact, this has been reported regularly since 1960 , particularly in patent literature. In rare cases, the two polymers are prepared, without the addition of a third component, by different blending 

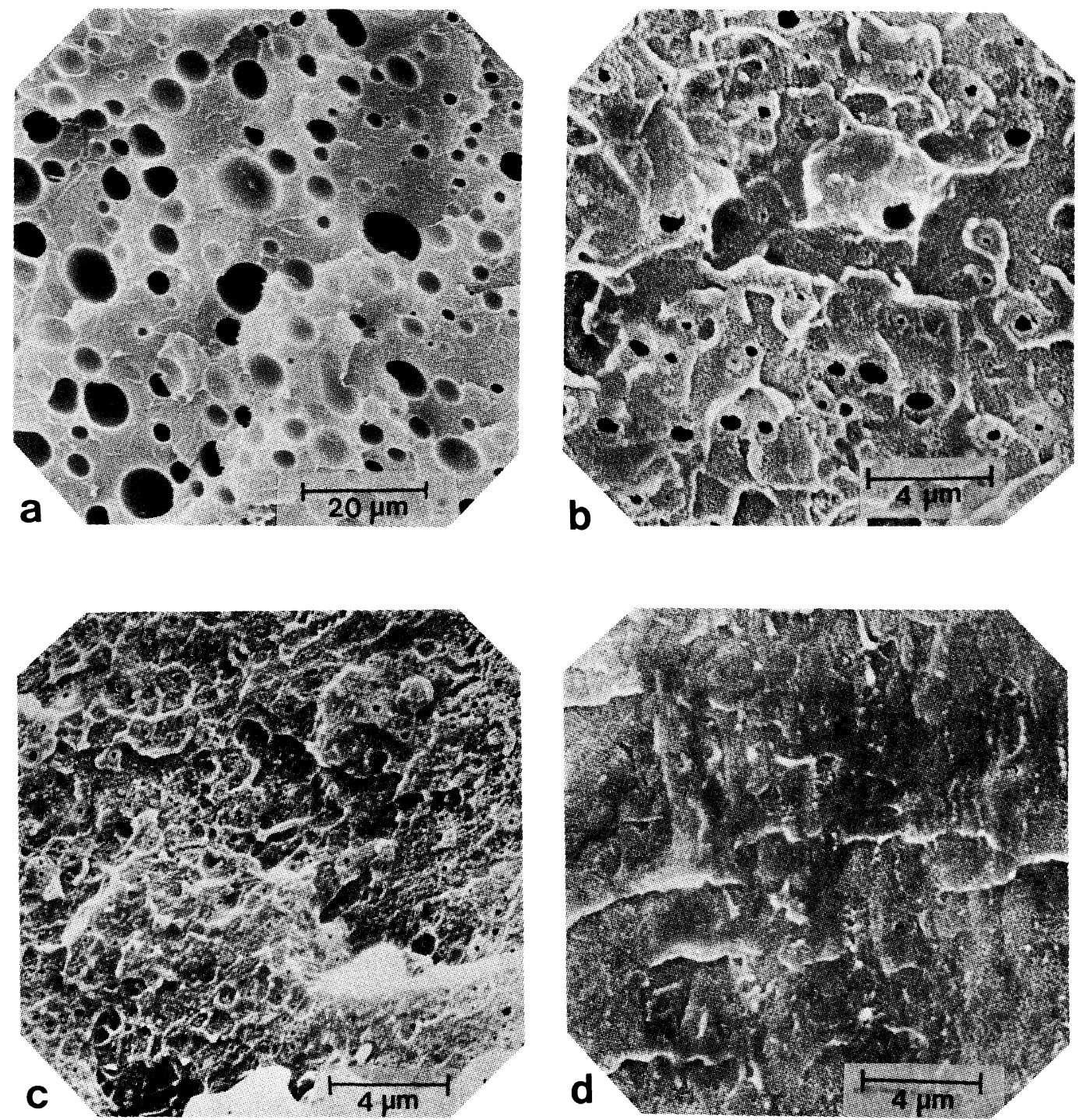

Figure 3. Scanning electron micrographs of fracture surfaces of blends, followed by minor phase dissolution: (a) PA6/PS (20/80), (b) PA6/SAA3 (20/80), (c) PA6/SAA10 (20/80), (d) PA6/SAA15 (20/80).

methods. ${ }^{11,12}$ More often the ethylene component is modified chemically ${ }^{13-16}$ or prepared in the form of a copolymer. For example, MacKnight et al. ${ }^{17}$ examined the morphology and mechanical properties of binary blends of PA6 as the major component and ethylenemethacrylic acid copolymer (EMAA) as the minor component. They found that the methacrylic acid content of the copolymer has pronounced effect upon the properties of the resulting blends. When PE was replaced by EMAA copolymer containing the $6.8 \%$ methacrylic acid, the average size of the minor phase was reduced to one-fourth. Recalling that the minor phase size of a PA6/SAA3 blend was one-twentieth of a PA6/PS blend, a SAA copolymer has a much stronger effect than EMAA copolymer in controlling phase mor- 
phology.

Figure 3 shows the morphology of PA6/PS (20/80) and PA6/SAA's (20/80) blends in which the PA6 forms a dispersed phase. Here it can also be noted that dispersed phase size is significantly reduced as AA content in SAA is increased.

The dramatic effects of the AA units in copolymer on the morphology can be explained in terms of two major contributions. There may exist some specific interactions, such as the formation of hydrogen bonds between the PA6 and SAA copolymer phases. Such intermolecular interactions have been shown important in the compatibilization of polymer blends. ${ }^{17}$ Another is the possibility of chemical reactions between the amine end groups of PA6 and the carboxylic acid of SAA during melt mixing. In a study on the binary blends of PA6 and EMAA, MacKnight et $a l .{ }^{18}$ suggest that graft copolymers are formed between two phases as a result of chemical reactions taking place during melt mixing. Such graft copolymers can act as an effective compatibilizer for the blend. Therefore, in PA6/SAAs blends, it is possible to form graft copolymers which contribute to decrease in dispersed phase size. The repulsion effect between styrene and acrylic acid units in SAA copolymer may also play a role in compatibilization, as in the case of blends of polycarbonate and poly(styrene-comethacrylic acid $)^{19}$ in which polycarbonate is miscible with poly(styrene-co-methacrylic acid) whereas polycarbonate is not miscible with polystyrene.

\section{Rheological Properties}

Complex viscosities are plotted against frequency for PA6/PS and PA6/SAA's blends in Figures $4-7$. It is observed that the observed viscosity of PA6/PS (80/20) blends was lower than that of PA6 and that yield ${ }^{20}$ was detected at low frequency range for 20/80 blend as shown in Figure 4. However the viscosity of the PA6/SAA's blend was higher at certain compositions than that of SAAs at

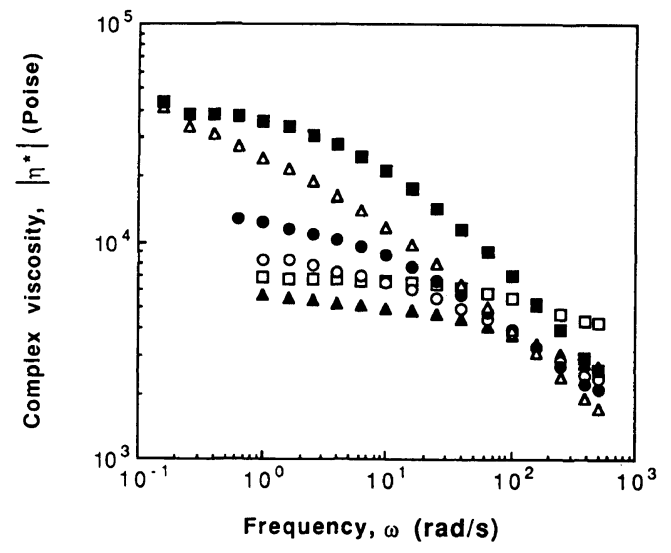

Figure 4. Complex viscosity vs. frequency for PA6/PS blends: ( $\square$ ) $100 / 0,(\Delta) 80 / 20,(\bigcirc) 60 / 40,(\bigcirc) 40 / 60,(\triangle)$ 20/80, (ロ) $0 / 100$.

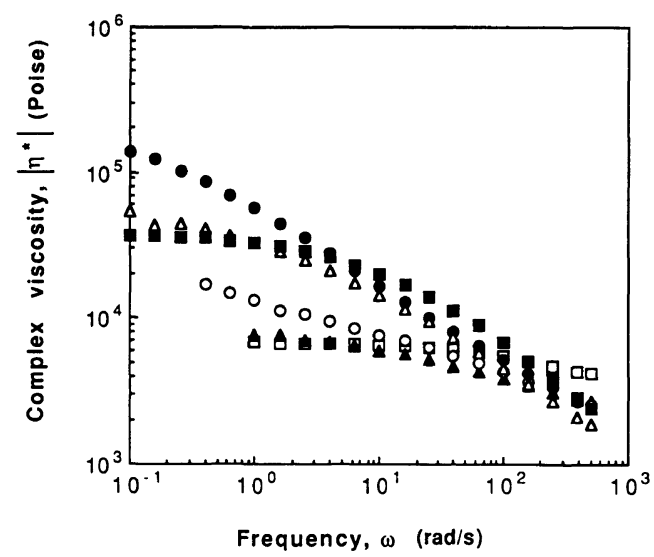

Figure 5. Complex viscosity $v s$. frequency for PA6/SAA3

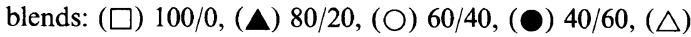
20/80, (ロ) $0 / 100$.

low frequency as shown in Figures 5-7. More specifically, as AA content in SAA increases, Newtonian viscosity behavior is progressively replaced by non-Newtonian power law behavior at low frequency. It is generally known that non-Newtonian power-law behavior at low frequency is due to heterogenity ${ }^{20}$ or the presence of very high molecular weight component in polymer liquids. According to a recent paper, ${ }^{21}$ this behavior can be also caused by long branching. Therefore, in our system, low frequency non-Newtonian power-law 


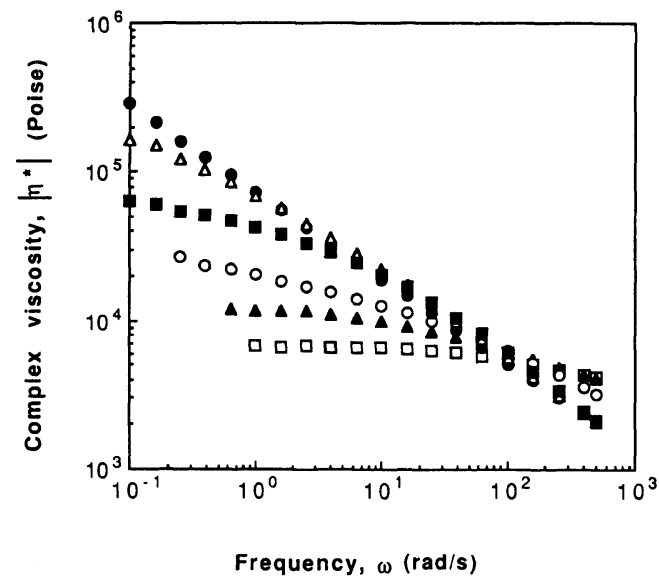

Figure 6. Complex viscosity $v$ s. frequency for PA6/SAA5 blends: ( $\square$ ) $100 / 0,(\boldsymbol{\Delta}) 80 / 20,(\bigcirc) 60 / 40,(\boldsymbol{O}) 40 / 60,(\triangle)$ 20/80, (ם) $0 / 100$.

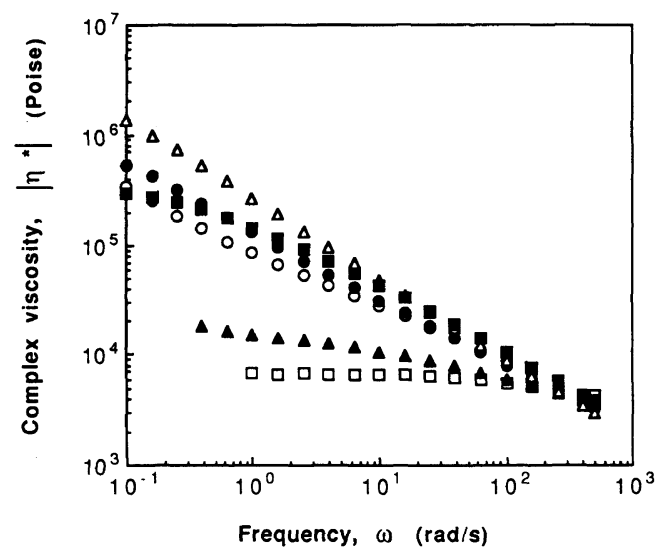

Figure 7. Complex viscosity vs. frequency for PA6/ SAA10 blends: ( $\square$ ) $100 / 0,(\boldsymbol{A}) 80 / 20,(\bigcirc) 60 / 40$, (O) $40 /$ 60, $(\triangle)$ 20/80, (ם) 0/100.

behavior seems attributed to both morphological heterogenity due to the immiscibility of two polymers and the molecular weight increase due to the long chain branching by the chemical reaction between amine groups of PA6 and carboxylic acid group of SAA in melt mixing. Figure 8 shows that the torque for mixing is higher for the PA6/SAA5 blend than for other blends, indicating that the chemical reaction between two polymers takes place to yield graft copolymers.

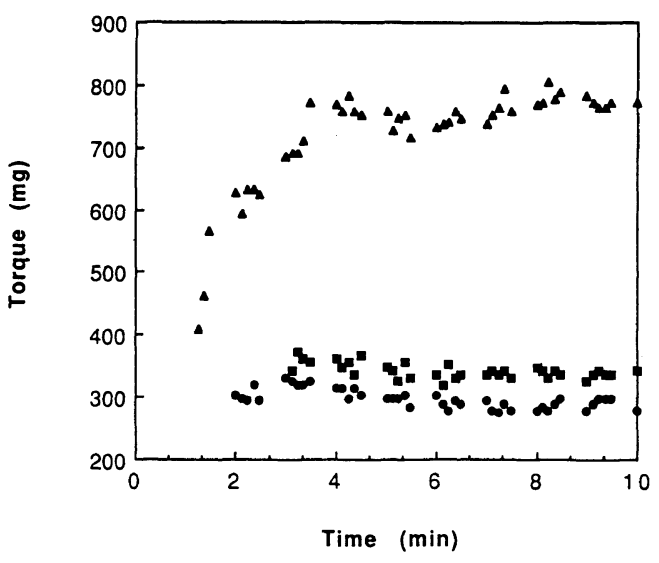

Figure 8. Torque changes $v s$. time: (ם) PA6/PS (80/20), (O) PA6/SAA3 (80/20), (A) PA6/SAA5 (40/60).

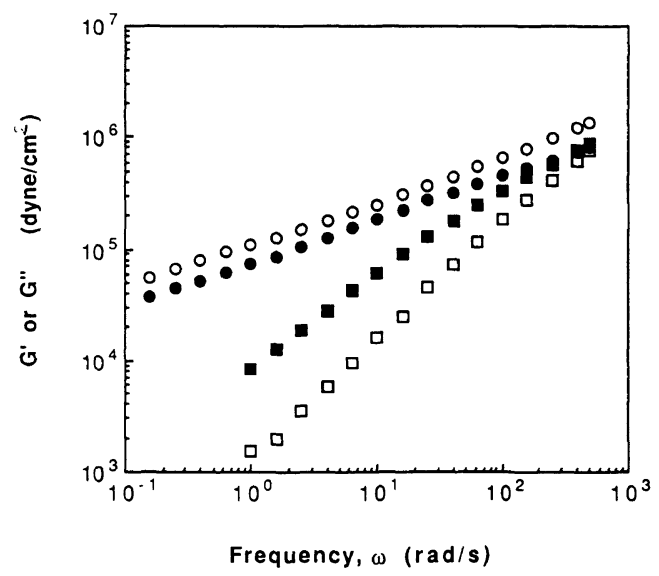

Figure 9. Comparison of $G^{\prime}$ and $G^{\prime \prime}$ curves $v s$. frequency for PA6/PS (60/40) blend (squares) and PA6/SAA10 (40/ $60)$ blend (circles). Open symbols are $G^{\prime}$ and filled symbols are $G^{\prime \prime}$.

Harrell and Nakajima reported that a $G^{\prime}$ and $G^{\prime \prime}$ versus frequency plot can be used for analyzing the effects of degree of branching. ${ }^{21}$ The low frequency storage modulus increases with long branching, and thus for an extreme case, $G^{\prime}$ response dominates over the entire range of observed frequencies; i.e., no $G^{\prime}-G^{\prime \prime}$ crossover is observed. When $G^{\prime}$ and $G^{\prime \prime}$ are plotted against frequency for our system, the extremes in the type of viscoelastic behavior associated with the linear or most extensively 
branched sample are clearly seen in Figure 9. For the PA/PS (60/40) blend, a crossover of $G^{\prime}(w)$ and $G^{\prime \prime}(w)$ is observed, while for the PA6/SAA10 (40/60) no crossover is observed, suggesting that the PA6/SAA10 blend has long branches which form during processing. These results are in contrast to those reported by others from studies of linear and star branched polystyrene ${ }^{22}$ and polybutadiene. ${ }^{23}$ They also observed some enhancement of $h_{\mathrm{o}}$ and broadening of the relaxation spectrum resulting from the introduction of branching. However, accompanying change in the $G^{\prime}$ contribution relative to that of the $G^{\prime \prime}$ was not so apparent compared with our study.

\section{Mechanical Properties}

In the case of ideal mixing behavior, it is reasonable to expect that the mechanical properties of the blend $M$ follow the simple rule of mixing:

$$
M=\Phi_{1} M_{1}+\Phi_{2} M_{2}
$$

where $\Phi_{i}$ and $M_{i}$ are the volume fraction and considered property of component $i$, respectively. Incompatible polymer blends form multiphase materials and thus exhibit mechanical properties that are normally below those predicted by the simple rule of mixing as a result of poor adhesion between phases. ${ }^{24,25}$ However, compatible blends, which show also separate phases, often exhibit mechanical

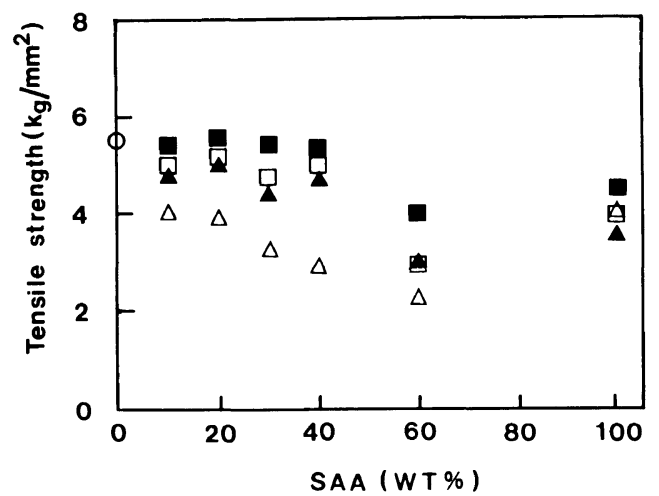

Figure 10. Tensile stength of PA6/SAA's blends: $(\triangle)$ PS, (A) SAA3, ( $\square$ ) SAA10, (ם) SAA15. properties that closely follow the simple rule of mixing when prepared under adequate phase dispersion and mixing conditions. ${ }^{9}$

The tensile strength, modulus and elongation at break of the PA6/PS blend and PA6/SAAs blends are shown in Figures $10-12$, respectively. As shown in the Figures, the PA6/PS blends show strong negative deviation from the simple rule of mixing, while the PA6/SAA3 blends show a small negative deviation from the rule. Moreover, the tensile strength and modulus of PA6/SAA's blends follow the simple rule of mixing more closely as AA content in SAA compolymer increases.

It is widely accepted that in two-phase polymeric systems, the particles of the dispersed phase act as stress concentrators,

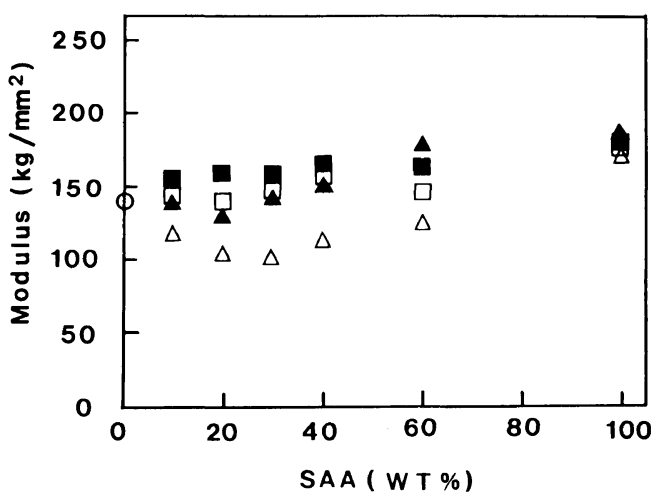

Figure 11. Modulus of elasticity of PA6/SAA's blends:

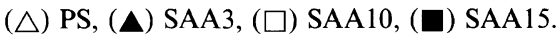

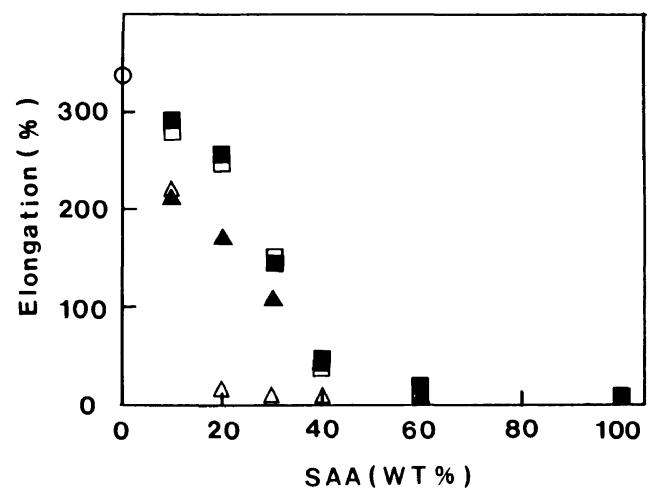

Figure 12. Elongation at break of PA6/SAA's: $(\triangle)$ PS, (A) SAA3, ( $\square$ ) SAA10, ( $\square$ ) SAA15. 
introducing weak points in the material. As a result, an intrinsically tough matrix breaks at lower stress and at lower elongation compared to a material free from the particles. If a large number of cracks are present per unit volume, however, their stress fields can interfere as they pass near one another. This type of interaction strongly reduces stress at the tips of the cracks and stops their growth. Since more cracks are formed during the fracture process, more energy would be absorbed in breaking the material, and elongation at break would be higher. Therefore, it is expected that the tensile strength and elongation at break of PA6/PS blends are lower than those of PA6/SAA's blends, since the particle size of PA6/PS blends is larger than that of PA6/SAA's blends, i.e., the number of dispersed particles per unit volume is smaller in the PA6/PS blends than in the PA6/SAA's blends.

\section{CONCLUSIONS}

The introduction of AA unit in PS is very effective for controlling the morphology of polyamide 6 and styrene polymer blends. The domain size of the dispersed phase of PA6/SAA's blends decreases with increasing AA content in SAA copolymer, while PA6/PS blends show typical morphology of an incompatible blend. Moreover, the fracture surface of a PA6/SAA15 blend shows no discernible domains, indicating good compatibility at the magnification in this study. Reological properties of the blends provide evidence for the formation of long branching between the amine end groups of PA6 and the carboxylic acid of SAA during melt mixing. It seems that the formation of long branching contributes to the compatibility of PA6/SAA's blends.

Decrease in the domain size of the dispersed phase results in an improvement in the tensile properties of PA6/SAA's blends. The tensile strength and modulus of PA6/SAA's blends follow the simple additive rule of mixing more closely as the AA content in SAA copolymer increases, while PA6/PS blends show a strong negative deviation from the simple additive rule of mixing.

\section{REFERENCES}

1. F. Ide and A. Hasegawa, J. Appl. Polym. Sci., 18, 963 (1974).

2. E. Nolley, J. W. Barlow, and D. R. Paul, Polym. Eng. Sci., 20, 364 (1980)

3. C. R. Rindsey, D. R. Paul, and J. W. Barlow, J. Appl. Polym. Sci., 26, 1 (1981).

4. W. E. Baker and M. Saleem, Polymer, 18, 2057 (1987).

5. R. Fayt. R. Jerome, and Ph. Teyssie, J. Polym. Sci., Polym. Phys. Ed., 20, 2209 (1982).

6. D. Heikens and W. Barentsen, Polymer, 18, 69 (1977).

7. D. Heiken, N. Hoen, W. Barentsen, P. Piet, and H. Laden, J. Polym. Sci., Polym. Symp., 62, 309 (1978).

8. W. N. Barentsen, D. Heikens, and P. Piet, Polymer, 15, 119 (1974)

9. S. Endo, K. Min, J. L. White, and T. Kyu, Polym. Eng. Sci., 26, 45 (1986).

10. W. H. Jo, S. C. Lee, and M. S. Lee, Polymer Bulletin, 21, 183 (1989)

11. H. Craubner and G. Illing, German Patent, 1, 131, 883 (1962).

12. M. R. Kamal, I. A. Jinnah, and L. A. Utracki, Polym. Eng. Sci., 24, 1337 (1984).

13. F. P. Lamantia, A. Valenza, and D. Acierno, Colloid Polym. Sci., 263, 726 (1985).

14. Y. J. Kim, C. D. Han, B. K. Song, and E. Kobassi, J. Appl. Polym. Sci., 29, 2359 (1984).

15. H. K. Chuang and C. D. Han, J. Appl. Polym. Sci., 30, 165 (1985).

16. C. D. Han and H. K. Chuang, J. Appl. Polym. Sci., 30, 2431 (1985).

17. E. J. Moskala, S. E. Howe, P. C. Painter, and M. M. Coleman, Macromolecules, 17, 1671 (1984).

18. W. J. MacKnight, R. W. Lenz, P. V. Musto, and R. J. Somani, Polym. Eng. Sci., 25, 1124 (1985).

19. S. Akiyama, K. Ishikawa, and H. Fujishi, Polymer, 32, 1673 (1991)

20. C. D. Han and T. C. Yu, Polym. Eng. Sci., 12, 81 (1972).

21. E. R. Harrell and N. Nakajima, J. Appl. Polym. Sci., 29, 995 (1984).

22. T. Masuda, Y. Ohta, and S. Onogi, Macromolecules, 4, 763 (1971).

23. W. E. Rochefort, G. C. Smith, H. Rachapudy, V. R. Raju, and W. W. Graessley, J. Polym. Sci., Polym. Phys. Ed., 17, 1197 (1979).

24. D. R. Paul, C. E. Vinson, and C. E. Locke, Polym. Eng. Sci., 12, 157 (1972).

25. E. Perry, J. Appl. Polym. Sci., 8, 2605 (1964). 